\title{
A SKINNER BOX RECORDER FOR THE BLIND STUDENT ${ }^{1}$
}

\author{
WILBERT S. RAY \\ Bethany College
}

\begin{abstract}
Two audio oscillators, of different pitches, were wired to a tape recorder to give a permanent record of rate of bar pressing.
\end{abstract}

It was pointed out in a previous communication (Ray \& McDonald, 1971 ) that it is possible for a blind student, working alone, to carry out much of the training in a Skinner Box which the sighted student can perform. However, at the time of that report there was no available method of producing a record which the blind student could read. This note describes such a recorder. ${ }^{2}$

Two audio oscillators, emitting pulses at different frequencies, were wired to the microphone input of a magnetic tape recorder. One oscillator was pulsed by a time signal every 30 secs., the other by the rat's depression of the lever. When the tape was played back the two sounds were quite distinct, and the student could count the number of lever presses per unit of time, giving the operant level and the change in rate as training proceeds. Bar presses sometimes occur at a rate too high to count, but this may be taken care of by recording at a high rate of tape travel and playing back at a lower rate.

Allied-Radio Shack puts out a "Science Fair" "Organ Module" kit, which was very convenient here-especially as it costs only $\$ 6$. The oscillators used were at the ends of the one octave provided. A $10 \cdot \mathrm{ohm}$ resistor wired into the circuit in place of the speaker took care of impedance demands.

\section{REFERENCES}

RAY, W. S., \& McDONALD, C. E. 1971. The blind student and the Skinner Box. The Psychological Record, 21, 35-36.

\footnotetext{
' Requests for reprints may he addressed to Wilbert S. Ray, Bethany College, Bethany, West Virginia 26032. This is a report fr'm the Committer on Apparatus for the Blind of the Division on the Teaching of Psychology of the American Psychological Association.

2 We are grateful to D. M. Grady of BRS-Foringer for making the oscillator suggestion to us.
} 